\title{
Abdominal Hydatidosis-A Rare Presentation
}

\author{
Khadka H ${ }^{1}$, Sharma $\mathrm{S}^{1}$, Shrestha $\mathrm{SB}^{2}$ \\ ${ }^{1}$ Department of Radiology and Imaging, Bir Hospital, National Academy of Medical Sciences \\ ${ }^{2}$ Department of Surgery, Nepal Police Hospital, Kathmandu, Nepal
}

Received: March 20, 2018

Accepted: April 30, 2018

Published: June 30, 2018

Cite this paper:

Khadka H, Sharma S, Shrestha SB. Abdominal Hydatidosis-A Rare Presentation. Nepalese Journal of Radiology 2018;8(11):37-40.http://dx.doi.org/10.3126/njr.v8i1.20455

\begin{abstract}
Hydatid disease may develop in almost any part of the body. Approximately $70 \%$ of the hydatid cysts are located in the liver followed by the lung (25\%). The kidneys, spleen, mesentery, peritoneum, soft tissues and brain are uncommon locations for hydatid cysts. Involvement of pelvis is very rare, with ovary the most frequently involved genital organ. We report a rare case of abdominal hydatidosis with cysts in the liver, spleen, peritoneal cavity and ovary.
\end{abstract}

Keywords: Abdominal hydatidosis; Liver hydatid; Pelvic hydatid; Ovarian hydatid

\section{INTRODUCTION}

Hydatid disease is caused by Echinococcus, parasitic tapeworm, and can occur anywhere from head ${ }^{1}$ to toe. The most frequently involved organs are liver (55-70\%) followed by lung (18-35\%). These two organs can be affected simultaneously in about $5-13 \%$ of cases. ${ }^{2}$ Although no site in the body is completely immune from it. ${ }^{3}$ Pelvic hydatid is considered an extremely rare condition occurring in $0.3-4.27 \%$, ovary seems to be the most frequent genital organ involved and constitute approx $0.2 \%$ of different hydatid disease location. ${ }^{4}$ Laparotomy is the most common surgical approach. Conservative procedures such as cystectomy and omentoplasty for hydatid disease should

Correspondence to: Dr. Hensan Khadka

Department of Radiology and Imaging

Bir Hospital

National Academy of Medical Sciences

Kathmandu, Nepal

Email:hensankhadka@yahoo.com be the standard surgical procedure because of their safety, simplicity, and effectiveness in fulfilling the surgical treatment criteria of hydatid disease. PAIR (Puncture, Aspiration, 
Injection and Reaspiration) is now preferred for less invasive management of hydatid cyst fulfilling the criteria. Cerebral Hydatid cysts occur in only $2 \%$ of all the cases reported, middle cerebral artery distribution is most frequently involved. ${ }^{3}$ Cardiac involvement is very rare $(0.02 \%-2 \%)$ and most commonly affects the left ventricle in $(50 \%-60 \%)$ of cases. ${ }^{3}$ Multiple hydatid cysts may resemble multiloculated mass filling entire peritoneal cavity referred as peritoneal hydatidosis. ${ }^{1}$

The diagnosis is easier when the lesion has multiple locations involving different organs or when daughter cysts, germinal membrane detachment and calcification are present. ${ }^{5}$ Atypical and rare presentations of disease may be seen in kidneys ( $3 \%)$, usually the upper and the lower pole of the kidney may be involved. ${ }^{5}$

\section{CASE REPORT}

A $20 \mathrm{y}$ old female presented to hospital with vague pain abdomen and abdominal distension for one year. Her periods were irregular. Routine blood and urine investigations were normal. Ultrasonography showed multiple thick walled cystic lesions in both lobes of liver, spleen, right paracolic gutter, lesser sac and one cyst in left adnexa with ovary not separately identified. No calcification seen. The largest cyst measured approximately $108 \times 86 \mathrm{~mm}$ in right paracolic gutter. One of the cysts in liver revealed detached membranes. Left adnexal cyst appeared as simple cyst, measuring approximately $35 \times 30 \mathrm{~mm}$. CT scan showed similar findings of multiple thick walled cysts with no calcification in any of them. None of these had daughter cysts. Immune assay( Ig G) for echinococcus was significantly high(38.7). Exploratory laparotomy was done which confirmed the imaging findings of multiple intraabdominal hydatid cysts including one in left ovary.

\section{DISCUSSION}

Hydatid disease is often seen in areas where sheep breeding is common. Use of ultrasound has made possible an earlier diagnosis before serious complications. Apart from common sites such as liver and lungs, hydatid cysts can present in unusual sites which include spleen, peritoneum, kidney, muscle, adrenal gland, ovary, pancreas, thyroid gland, pleura, diaphragm, uterus and brain. ${ }^{6}$ Peritoneal hydatid disease represents an uncommon occurrence and its diagnosis is more accurate today due to the new imaging techniques. Cysts in the peritoneal cavity account for 10$16 \%$ of cases in literature and mainly result from rupture of concomitant liver cysts. ${ }^{7}$ Primary peritoneal echinococcosis accounts for $2 \%$ of all abdominal hydatidoses. ${ }^{8}$ Onset of symptoms of hydatid cysts are nearly always hepatomegaly and abdominal palpable mass. ${ }^{9}$ There is a case report with more than 1000 intra-abdominal hydatid cysts.

We reported this case because of its rarity with involvement of multiple organs such as liver, spleen, peritoneum and ovary. Pelvic hydatid is very rare. It can be primary and more commonly secondary. Pelvic echinococcosis symptomatology is nonspecific and may include pain, menstrual irregularities, infertility and urinary symptoms. Ovarian hydatid may mimic polycystic ovary, ovarian malignancy or simple ovarian cyst in imaging.

Ultrasonography and computerized tomography are most useful in establishing diagnosis of hydatid disease. CT is more sensitive and accurate compared to ultrasound. ${ }^{10}$

The type of the imaging modality used depends on the site and the size of the hydatid cyst. Ultrasonogarphy is the first line of screening for abdominal hydatidoses and is especially useful for detection of detached membranes (Figure 1), septas and hydatid sand. It can 
also depict daughter cysts. CT scan best demonstrates cyst wall calcification and cyst infection. CT scan is also the modality of choice in peritoneal seedling. ${ }^{1} \mathrm{CT}$ shows well defined solitary or multiple cysts that may be thin walled or thick walled (Figure 2 and 3).

USG is low cost and has high sensitivity. It allows five sonographic types of hepatic hydatid disease, as follow:

Type I-purely unilocular cyst

Type II-Cyst with a floating membrane

Type III-Cyst with daughter cysts

Type IV-Heterogenous mass

Type V-Calcified cyst
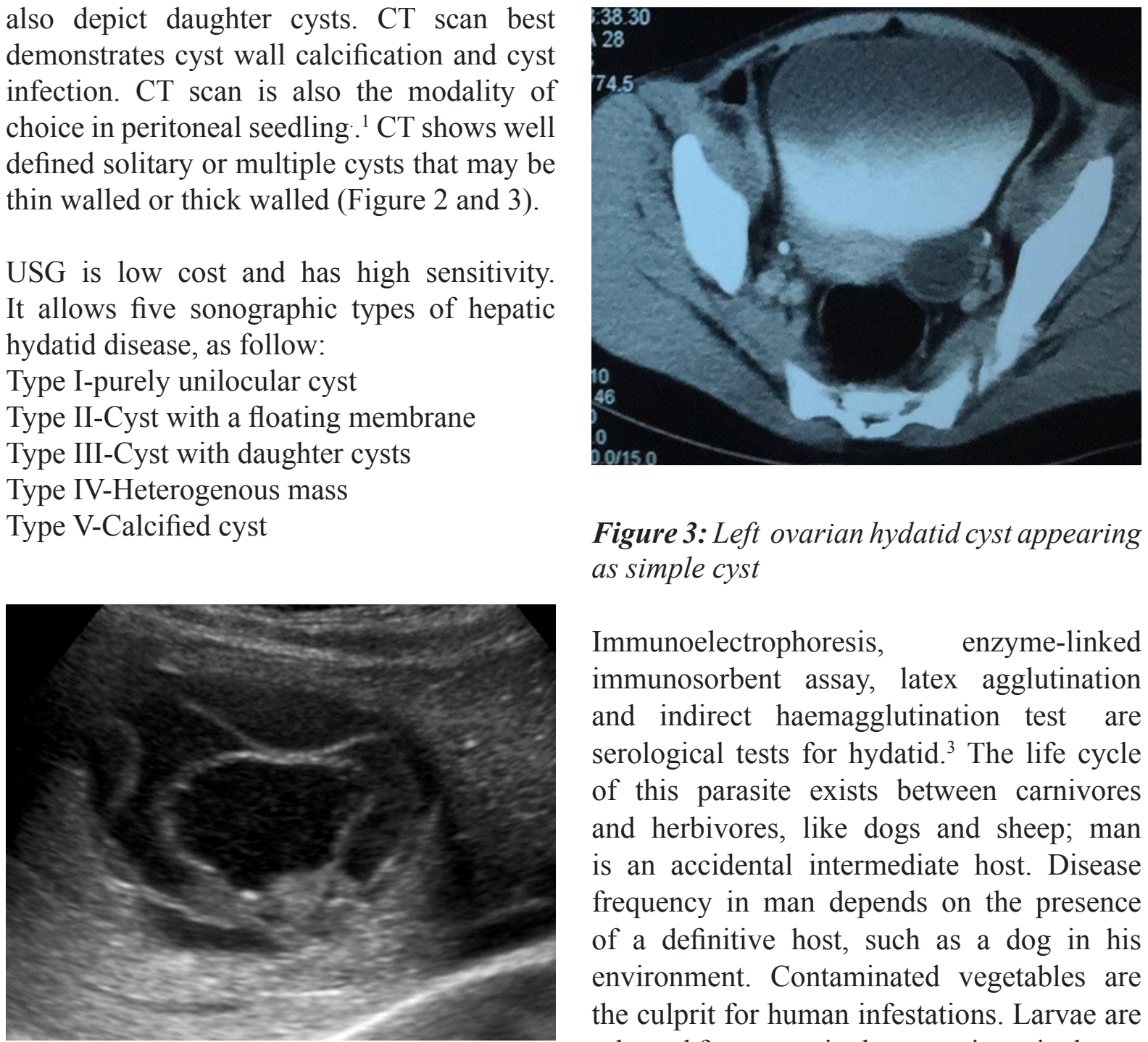

Figure 3: Left ovarian hydatid cyst appearing as simple cyst

Immunoelectrophoresis, enzyme-linked immunosorbent assay, latex agglutination and indirect haemagglutination test are serological tests for hydatid. ${ }^{3}$ The life cycle of this parasite exists between carnivores and herbivores, like dogs and sheep; man is an accidental intermediate host. Disease frequency in man depends on the presence of a definitive host, such as a dog in his environment. Contaminated vegetables are the culprit for human infestations. Larvae are released from eggs in the gastrointestinal tract

Figure 1: Hydatid cyst of liver with detached internal membrane

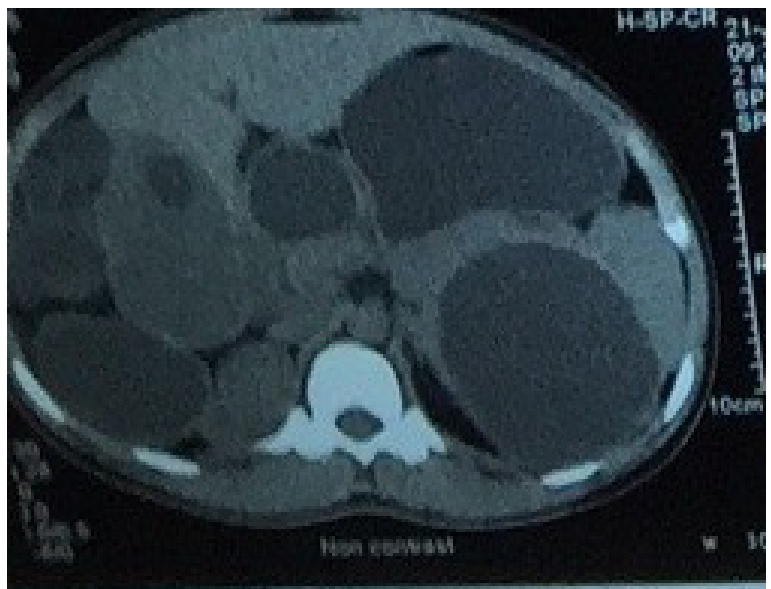

Figure 2: Peritoneal hydatidosis with splenic cyst

of man and other intermediate hosts, passing through the intestinal wall, and reaching the portal vein. Thus, the liver is the first and most common site of the disease. Some larvae may even pass into the lungs, reach the left side of the heart and the systemic circulation, and then they may lodge in any tissue except hair, nails and teeth.

\section{CONCLUSION}

Discovering hydatid cyst in pelvic cavity especially as primary localization, is a rare event. The ovarian involvement is often secondary to cyst's dissemination localized in different site. Ovarian hydatid can mimic simple ovarian cyst and high index of suspicion is needed to diagnose this entity. 


\section{CONFLICT OF INTEREST}

None

\section{SOURCES OF FUNDING}

None

\section{REFERENCES}

1. Karadag O, Gurelik M, Ozum U, Goksel HM. Primary multiple cerebral hydatid cysts with unusual features. Acta Neurochir (Wien) 2004;146(1):7377. https://doi.org/10.1007/s00701-003$\underline{0169-0}$

2. KirA, Baran E. Simultaneous operation for hydatid cyst of right lung and liver. Thorac Cardiovasc Surgeon 1995;43:62-64. https://doi.org/10.1055/s-2007-1013772

3. Husen YA, Nadeem N, Aslam F, Bhaila I. Primary splenic hydatid cyst: a case report with characteristic imaging appearance. $J$ Pak Med Assoc 2005;5:219-221. Available from: http://www.jpma.org. pk/full article text.php?article id=746 [Accessed 20th Feb 2018].

4. Fantassi R, TurkiE, Majdoub W, Hammimi S, Hajji M. Primary ovarian hydatid cyst: A case report and review of literature. Insights Reprod Med 2017;1:1-5. Available from: http://www.imedpub. com/articles/primary-ovarian-hydatidcyst-a-case-report-and-review-ofliterature.php?aid $=19602$ [Accessed 20th Feb 2018].

5. Polat $\mathrm{P}$, Kantarci M, Alper F, Suma S, Koruyucu MB, Okur A. Hydatid Disease from Head to Toe. Radiographics 2003;23:475-494. https://doi.org/10.1148/rg.232025704

6. Abu-Eshy SA. Some rare presentations of hydatid cyst (Echinococcus granulosus). $J$ R Coll Surg Edinb 1998;43(5):347-352. Available from: https://www.ncbi.nlm. nih.gov/pubmed/9803111 [Accessed 20th Feb 2018].
7. Prousalidis J, Tzardinoglou K, Sgouradis L,Katsohis C, Aletras H. Uncommon sites of hydarid disease.World J Surg 1998;22:17-22. https://doi.org/10.1007/s002689900343

8. Singh RK. A case of disseminated abdominal hydatidosis. $J$ Assoc Physicians India 2008;56:55. Available from: https://www.ncbi.nlm.nih. gov/pubmed/18472505 [Accessed 20th Feb 2018].

9. Inan M, Ayvaz S, Baser M et al. Hepatic hydatid disease in children and adults living in different areas in Turkey. Saudi Med J 2007;28(4):555-558.

10. Çol C, Çol M, Lafni H. Unusual localizations of hydatid disease. Acta Medica Austriaca 2003;30:61-64. https://doi.org/10.1046/j.1563$\underline{2571.2003 .30081 . x}$ 